\title{
Love and Money
}

We have been exploring how identities develop within the matrices available to us as humans in a world formulated by Western culture, specifically the Enlightenment and colonialism. I have been arguing that the liberal subject of this history is gendered cis male and raced white, and is dependent on binary thinking to keep his self and the systems that build and run his world intact. A theory of human complicity seeks to challenge this modus operandi, and to suggest that in practice, human being is a much more complicated and enmeshed process. Binary-structured subjectivity is an invested fiction. Oppression and suffering are caused by the processes of othering that result from the version of human being this dominant culture has evolved to experience as natural. I have been suggesting that to resist this process of othering is to think differently about what it means to be human. It is to see that we are dependent on each other to be ourselves. As such, we are made by and continue to make this world, and we can change it, but we have to move beyond the terms it wants to give us. Articulating this vision requires bringing knowledge developed in the humanities to the psy disciplines to complement some of the knowledge already in circulation in psychology, through attachment theory, object relations psychoanalysis or interpersonal 
neurobiology, for example. How these approaches relate to a complicit frame for therapeutic practice is taken up in the next chapter.

This chapter explores how neoliberalism, the late capitalist instantiation of the systems we have been exploring, interacts with social media, a relatively new technology at this stage of the West's game. It suggests some consequences for relational human being. The chapter comments on how by now, the logic of profit is woven into personal relationships in ways this late capitalist culture takes for granted, and the internet exploits.

I suggest that the atomization of experience and the ferocious pressure to perform a self for (emotional, social and economic) profit enabled by the direction social media has taken is a result of a specifically American understanding of what it means to be a person: liberally individualist, and invisibly gendered and raced. This is affecting young Americans in generationally specific ways, with specific consequences for how identity becomes available to the self; in short, for ways of being human today that pull away from complicitous knowing and toward an intensified, commodified individualism, with all the implications for human systems that we have been exploring. The current context, of neoliberal economic pressures and the cultural and psychological formations they create, together with the turn technology has taken in the last 20 years, creates a specific environment within which human relations and human being must form.

Although anxiety about the effects of technology on human systems is not new (Mokyr et al., 2015), there is arguably something unique about the turn that current uses of technology have taken. As my analysis will show, I am not optimistic about where things are going for young Western subjects. I will argue that the use of technology in the context of a neoliberal world order "has ushered in new organizing principles and new configurations of the self and human relationships" (Goodman, 2020, p. 333), as a lesson in how the systems I have been tracking are taking their most modern form. At the least, psychotherapists can benefit from interrogating these processes and from being aware of how the psy disciplines continue to participate in them. 


\section{Neoliberalism and Identity}

Neoliberalism fractures social formations into individualized units, and focuses on competition as a force that will bring out the best in individuals, formulated in the first place as market participants. We all become entrepreneurs, responsible for our own economic survival, not entitled to rely on the state or its systems for help. In Chap. 2, we reviewed the basic definition of neoliberalism as a system that is both political and economic, and its emergence from a set of historical circumstances that went on to occlude themselves, as neoliberalism presents itself as the natural and obviously best way to do things (Rutherford, 2018). Indeed, one of the things neoliberalism does so well is to render all aspects of life depoliticized by normalizing a brutal economic status quo which replaces the state, and obviates its responsibilities to citizens by extending to us an illusion of choice. As Zuboff (2019) maps in detail, capitalism is not just an economic system. It creates social reality and culture. And neoliberalism laid the groundwork for a new kind of capitalism, which uses the technology of the twenty-first century to form its subjects.

Within neoliberal logic,

[T] he market is construed as something that is natural to human beings. We tend to believe the mythology that markets are natural because we are now constituted as members of society according to market terms... Neoliberalism, as such, is competitive citizenship and consistently demands more competition in every area of our lives. We are on an endless hamster wheel. There is no steady ground. (Perry, 2018, p. 100)

For younger people especially, who have become subjects in the context of neoliberal systems since around 1980, life can often be fraught with anxiety; indeed, they have been called "the most anxious generation in history," an assessment linked to the impact of social media on their social-emotional development (Docu, 2018, p. 2; see APA, 2018). Schore (2012, p. 18) calls the levels of emotional distress in American youth, "this crisis at the core of our culture." They have been told that empowerment is their birthright and their responsibility (Rutherford, 2018), and that hard work will deliver success. Failure becomes a reflection of 
personal inadequacy, as structural limitations are rendered invisible (Sweet, 2018). Success and failure, because market terms are naturalized and reach deeply into aspects of life that used to be private, are both economic and psychological, and the two are entwined, as I will argue below.

It is within this context that the psy disciplines-whence comes the popular concept of identity in the first place (Erikson, 1968)-have helped to create an intensified version of the individual subject who is responsible for their own happiness, and for whom self-improvement is the means to manage psychological distress. Distress is conceived of as a personal issue, as the neoliberal subject does not have access to structural causes to explain their suffering. In the popular imagination and in many of the manualized approaches, psychological interventions aim at behavior changes and at helping clients find internal resources to achieve their goals, in workplace jargon which is a metric of psychic success. The focus on chemical causation for mental health symptoms helps clients achieve a sense of control over what is apparently not working correctly in their brains, without the requirement to investigate emotional processes, structural brutality or deeper pain or trauma (Davis, 2020). Such approaches help reinforce an enterprise culture where depth work is irrelevant (Sugarman, 2020).

Rose (1998, p. 153) details how enterprise culture emerged as a fundamental concept of neoliberal theorists, where,

[T] he well-being of both political and social existence is to be ensured not by centralized planning and bureaucracy, but through the "enterprising" activities and choices of autonomous entities-businesses, organizations, persons - each striving to maximize its own advantage by inventing and promoting new projects by means of individual and local calculations of strategies and tactics, costs and benefits.

The self that is successful in such a culture is able to "maximize its own human capital,... a self that calculates about itself and that acts upon itself in order to better itself" (Rose, 1998, p. 154). This way of thinking, of course, works well with the thinking developed in the psy disciplines; Rose (1998) argues that technologies of psychology were formative for enterprise culture. Specifically, Sugarman (2020) critiques positive 
psychology as a technique of commodification of happiness, and as a way of thinking that renders deep wellness irrelevant. Rose (1998) explores how social psychology helped produce individuality as a technology of control under the aegis of democratic knowing. He also focuses on how the scientific stance of the psy disciplines is productive, enabling "techniques that will shape, channel, organize, and direct the personal capacities and selves of individuals under the aegis of a claim to objectivity, neutrality, and technical efficacy" (Rose, 1998, p. 155). Rutherford (2018), Sugarman (2020) and Melluish (2014) all hold the psy disciplines accountable for how they have perpetuated a model of the selfcontained individual, responsible for their own choices, given how this plays into neoliberal ideologies. Gill and Orgad (2018) explore the arrival of the concept of resilience to the work of neoliberalism, part of what they term the psychological turn within neoliberalism. They trace how issues of character have become part of the discourses of neoliberalism via discourses and practices of psychology.

There is no doubt that psy approaches have helped to inform what Davies (2016) calls the Happiness Industry. Rose (1998, p. 157) links the imperative to happiness with the role of psychological experts in helping to create individuals tasked with their own improvement:

Contemporary individuals are incited to live as if making a project of themselves; they are to work on their emotional world, their domestic and conjugal arrangements, their relations with employment and their techniques of sexual pleasure, to develop a "style" of living that will maximize the worth of their existence to themselves... Although our subjectivity might appear our most intimate sphere of experience, its contemporary intensification as a political and ethical value is intrinsically correlated with the growth of expert languages, which enable us to render our relations with ourselves and others into words and into thought, and with expert techniques, which promise to allow us to transform our selves in the direction of happiness and fulfillment.

Like Rose (1998), Melluish (2014, p. 542) also focuses on the role of the psychological expert in the intensification of psychological techniques for and on personhood: 
Increasingly, there are branded therapies, branded research methods and a connected process of marketization. Estimates suggest that there are 100-140 different schools of psychological therapy... many branded in such a way that for a psychologist to use these ideas they are required to undergo specific accredited training. This proliferation of therapeutic models is in spite of the overwhelming evidence that common factors, principally the quality of the relationship between the therapist and the client, are more important than any specific differences in models.

Melluish (2014) also points out that these scientifically endorsed methods are exported from the West to the rest of the world. As such, they participate in globalized, neocolonial relations of power with the majority world.

These, then, are some of the qualities associated with the neoliberal self, formed in relation to the psychologized individual: enterprising, responsible for themself, energetic, ambitious, resilient, self-reliant, committed to improving as an investment in themself, flexible, mobile, calculating, active, goal-oriented, in control. Furthermore, these once-private personality traits must be displayed, in order for the neoliberal subject to ensure their marketability in this "contracting society" (Sugarman, 2020, p.76). Identity itself has been commodified:

An individual is properly understood to be an entrepreneurial self that needs to be branded, marketed, and sold on the open market... Selves are best thought of as consumer images that can be enhanced by purchasing the proper accoutrements or experiences. (Cushman, 2019, p. 261)

Or, as Horning (2015, n.p.) put it, “if your personality can't be leveraged - then authenticity is not really available to you. You can't afford to be yourself" (qtd. Sugarman, 2020, p. 78).

The new markers of personhood, "visibility and recognition," are conferred through networks, not communities, Sugarman (2020, p. 78) points out, until "visibility and self-image become the engine of community." This new kind of community is characterized by a broadness of reach but a shallowness of connection. As we will explore in more detail below, within neoliberalism and increasingly under the surveillance 
capitalism to which it helped give rise, particularly for those born into this world, identity has been commodified in specific ways. What used to be of value in private, personal terms, now acquires value in twenty-first century market terms, which "presume[...] the existence of property rights over processes, things, and social relations, [presume] that a price can be put on them, and that they can be traded" (Harvey, 2007, p. 165). As we saw in Chap. 2, such an ethics of human being for trade has emerged from historical processes that are economic and political. Perry (2018, p. 104) reminds us that, "the 'free' market as a theoretical framework depends on the 'unfreedom' of those who are on the margins or outskirts of market activity and who are often dominated by those who employ them or extract their labor." She points out that while more individuals are citizens now who would, at the start of modern capitalism, have been constitutive nonpeople to the Western colonially formulated state, they are subject to inherited economic inequalities, together with the increased and intense competition of neoliberalism. Zuboff (2019) likens the new system of capitalism that has grown out of the confluence of neoliberalism, the legal and political imperatives post-9/11, and the growth of machine learning, to the process of colonialism that birthed the modern subject. Late modernity, in this formulation, bears some resemblance to early modernity.

\section{The More Things Change}

Shakespeare's historical moment, the late sixteenth century, was the time Europe started moving in newly concerted way on what was to them, "the new world." It was the time when early modernity, with its colonizing and capitalist drives, began to develop the cultural forces that continue to mutate today. Liberal, Enlightened, colonizing modernity has its roots in Shakespeare's time. As always, cultural, economic and material developments co-constituted and all participated in this long transition (for a summary of how colonial discourses were developing in England at this time and how they fed into American life, see Kendi, 2016).

English itself was changing, part of a cultural shift that impacted England's sense of itself: access to literacy was increasing, and with it, a 
change to who wrote, and why. This fundamentally affected the allocation of authority. Whereas previously, only priests, monks and the aristocracy produced, consumed and circulated texts, with the advent of moveable type by Johannes Gutenberg in the mid-fifteenth century, it became easier and cheaper to print and disseminate writing. This commercial development worked together with the new sense of competitive national pride that emerged with proto-colonial expansion, and helped fuel access to literacy in languages other than Latin. There was a new excitement about what English might be capable of, and a concerted effort to demonstrate that new ways of communicating could enhance the culture. New technology, new ways to create and new identities fed into each other, illustrating Rose's (1998, p. 200, n2) point that technology "produces the possibility of humans relating to themselves as subjects of certain types," an argument I continue to make below.

One of these new ways of relating is seen in how, in Shakespeare's writing and that of his peers, a particular connection was made between relationships of love, and relationships meant to enable profit, as England transitioned from a feudal economy to what would become a capitalist one. Schalkwyk (2008) has explored the intertwining of what he calls the language of love and the language of service in Shakespeare's work. Shakespeare was one of a group of newly emergent hopefuls, craving recognition of their intellectual gifts and, from there, economic and social mobility in a changing world whose rules for how to achieve success were becoming less rigid and more full of possibility, less dependent on who you were born to and more malleable to what you might accomplish for yourself. Those up-and-coming men of a newly emerging class who were smart enough to develop a network they could exploit for economic gain could change their social standing. They had to invoke and perform specific versions of themselves and in so doing, of their relationships with the aristocratic men and women who had the economic and social means to advance the careers of their apparently devoted poets (Burke, 1997; Eisaman Maus, 1995; Ferry, 1983; Greenblatt, 1984; Huntington, 2001; Warley, 2005).

The development of the technology for print was an important component in this cultural change (Febvre \& Henri-Jean, 1979; Saunders, 1951). Once texts could circulate more freely, quickly and cheaply, which 
helped increase literacy in general, individuals could profit from the texts they produced in new ways (Marotti, 1995). Before this cultural development which quickly accrued economic imperatives, one did not think of oneself as the author of the text one produced in the sense we now take for granted after the Romantics. It was a display of one's learning, not plagiarism, to draw from and imitate the classics. Originality was not a thing. Certain forms, like drama and some kinds of elite poetry, were much more collaboratively produced than our later ideas about creative genius can accommodate (Marotti, 1986). The emergence of the personal identity of creator and author, and the profit to be gained from asserting this identity — both a psychological profit and an economic one-marked a huge shift in what it meant to write, to be addressed as a reader, to put one's work into the world (Fineman, 1986; Foucault, 1977; Greenblatt, 1984). Also to the point for the argument I want to make here, the development of print enabled the eventual constructions of modern publics, whether in the form of the nation, as Anderson (1991) has elucidated, or in the more diffuse and more modern sense of Warner's (2002) idea of the public sphere, on which more in a moment.

I have lived in four countries, and I have been struck since arriving in America by how profit is woven into personal relationships in ways this late capitalist culture takes for granted, in ways that remind me of patronwriter relationships in Shakespeare's proto-capitalist England. It is common sense that personal relationships should be pathways to economic advancement, that who you know is, and should be taken as, a valuable career resource. Part and parcel of this assumption is that how you present yourself, your personal narrative, should be carefully curated to present your best, most desirable, most valuable self to the world. Like Shakespeare's England, these cultural imperatives are facilitated by the expansion of new technologies of communication that fundamentally alter social, economic, educational, national and psychological dynamics.

In such a symbolic economy, relationships do not have value solely as themselves; they have commercial value as well, or instead. Human interactions have commodifiable potential, a fact that seems to be accepted as natural and obvious here in ways I have not experience elsewhere. If you want a job, you will likely not even be considered if you simply submit a resumé via the formal channels. Rather, you should approach someone in 
a position to give you that job or to introduce you to someone else who might. You approach them with strategic interest in who they are and what they have done. You approach them in the first place with your own personhood on offer, not your skills: They will help you if they like you. The purpose of the meeting or attempt to connect is not primarily to present what you can do, but who you are. If this meets with approval, you may get a step up in your career, or at least an addition to your network, which is useful because of how it may eventually yield career benefit. This is remarkably like the interweaving of the languages of love and service that Schalkwyk (2008) identified in Shakespeare's time. The personal is the commercial. The self is for sale, as is the very idea of human connection, which is assumed to exist for the purpose of profit as much as, if not more than, for its own sake. There is little intrinsic or implicit value in attachments in this universe outside of a capitalist logic. I am not suggesting intimate or family relationships are also this instrumentalized, although family connections are crucial to getting ahead in the networks that structure this country and its major institutions of power, from commerce, to elite universities, to the presidency. But certainly the ideas of friendship, and certainly the idea of what constitutes a public, are affected by this value system and this system of attributing relationship value as commodity value. If human connection is understood to be available for profit, then human selfhood is too, since the one depends upon the other.

Zuboff (2019, p. 44) tracks how neoliberalism has created an economic system which is explicitly "neofeudal" where wealth and power are consolidated in an elite, "far beyond the control of ordinary people and the mechanisms of democratic consent." In her account, the emotional malaise of the twenty-first century is a direct consequence of liberal subjects passing through neoliberal economic formations and their social and political consequence:

This is the existential contradiction...: we want to exercise control over our own lives, but everywhere control is thwarted. Individualization has sent each one of us on the prowl for the resources we need to ensure effective life, but at each turn we are forced to do battle with an economics and politics from whose vantage point we are but ciphers. We live in the knowledge that our lives have unique value, but we are treated as invisible... Our 
expectations of psychological self-determination are the grounds upon which our dreams unfold, so the losses we experience in the slow burn of rising inequality, exclusion, pervasive competition, and degrading stratification are not only economic. (Zuboff, 2019, p. 45)

This world produced what Zuboff (2019) calls surveillance capitalism, born of the way technology has been utilized to monetize our behaviors in an already neoliberal system which individualizes in order to exploit. Perhaps we are indeed returning to a version of a power hierarchy where love (friendship, connection, the meeting of curated selves for mutual profit) is money. The difference is that in Shakespeare's time, Western subjects were not yet Enlightened.

Zuboff's narrative traces the implications for subjects who have been formed in liberalism and capitalism. She (Zuboff, 2019, p. 189) invokes the internet as putatively "a mighty democratizing force that exponentially realizes Gutenberg's revolution in the lives of billions of individuals." But, she says, this potential has been colonized by the imperatives of surveillance capitalism, which uses the internet to collect information about us in order to render us the raw material of its profit-making. The small group of engineers who run this system are the new "narrow priesthood" (Zuboff, 2019, p. 189), akin to the priests of old whose preprinting press hold on literacy made them the mediators between ordinary people and their God. According to Zuboff (2019), Western culture has been quickly, oppressively and dishonestly altered by the ways the new technologies have come to be monetized. We are, she says, reverting to "a pre-Gutenberg order" (Zuboff, 2019, p. 189). The consequences for the kinds of subjects, the modes of human being, that are created accordingly are quite profound. We are left with senses of selves that expect to be autonomous and self-empowered, but are in fact radically hobbled by relations of power that we need in order to exist as subjects, but have no agency over, indeed, are controlled by.

If Shakespeare's time was emerging from feudalism and setting the stage for colonial expansion and all that came with it for the creation of modernity, then perhaps our time is indeed neofeudal, coming around in a loop to remake relationships for profit. How does one find oneself in a culture which is not only relentlessly selling one's connections, but one's identity? 


\section{Finding Oneself in the Public Eye}

Warner (2002, pp. 50-1) describes how publics are created by the mode of address that assumes them into existence, what he describes as the dilemma of the chicken and the egg:

Could anyone speak publicly without addressing a public? But how can this public exist before being addressed? What would a public be if no one were addressing it? Can a public really exist apart from the rhetoric through which it is imagined?... A public might be real and efficacious, but its reality lies in just this reflexivity by which an addressable object is conjured into being in order to enable the very discourse that gives it existence.

Publics are reliant on the words and images that call them into being, on the process of acting on the idea that they exist. A public can only exist as long as it is being addressed, and can only be invoked by its constituent members as long as they are paying attention (Warner, 2002). There is a precarity here that is also a condition of existence. There is also a clear sense of the imbrication of a public with its individual members. They make up each other. They make each other up. This dependent precarity is an excellent frame to bring to a discussion of the effects of the internet on the senses of selves of that group of younger people whose worlds are constituted by the idea of an online public.

Warner (2002) identifies several constituent factors to what makes up the idea of a modern public. These include the necessity of strangers to self-identity: in previous eras (Shakespeare's, too, Fiedler, 1973), the stranger was a threatening, external figure. The modern public relies on the idea of strangers out there who are like us, whose existence confirms our own. "In the context of a public," says Warner (2002, p. 56), "strangers can be treated as already belonging to our world. More: they must be. We are routinely oriented to them in common life. They are a normal feature of the social." As Warner (2002, p. 57) puts it, "strangerrelationality" is today "made normative, reshaping the most intimate dimensions of subjectivity around co-membership with indefinite persons in a context of routine action." Necessary to this process is the sheer fact of the ongoing attention of strangers, regardless of the "cognitive 
quality" of that attention. "Some kind of active uptake-however somnolent—is indispensable" (Warner, 2002, p. 61).

Written in 2002 (which Zuboff, 2019 times as the start of Google's consolidation of using surveillance to change the direction internet technology was taking), this certainly seems like a prescient description of how the online social media world has increasingly come to function, with quantifiable implications for those subjects formed within it (Calancie et al., 2017; Docu, 2018). Online profiles made to attract dates or sexual partners, networks of friends and their friends sought for the purposes of the upsell (personal or commercial), the use of Twitter to encourage fans who buy stuff to feel personally connected to the celebrity brand, the use of this technology to disseminate not only opinion, but now, political fiat, careers being made through blogs, the Instagramming of experience and the development of followers into both fame and, sometimes fortune, all of these depend on attracting the attention of strangers. It is the attention that matters, the attention that can be made into money and power.

Warner (2002) also explores the need for modern publics to be formulated by speech that is simultaneously both personal and impersonal. Public speech, says Warner (2002), must be understood by each of its addressees as being not exactly addressed to them, specifically, but to the stranger they were just before they were addressed, the stranger that makes possible the idea of a public to be addressed. Understanding that each addressee toggles between these two positions, strange and known, as a condition of being part of a public, is a conscious aspect of participation, he says. "The benefit of this practice is that it gives a general social relevance to private thought and life" (Warner, 2002, p. 58). Or, taken one step further, it brings private thought and life into the social as a means through which to connect with the public. This imbricates in very specific ways with the neoliberal puncturing of the sphere of the private. Private experience and personal identity become connected to the public realm through commercial imperative, which is experienced as natural, as an element of human being and relating.

To sum up: Warner (2002) offers one way to understand the pressure to be called into being as a successful self by seeing oneself in the public eye. He demonstrates the toggling between what he calls the personal and 
impersonal, as part of the condition of participation in this public. I suggest that what is going on with social media culture today is not a movement between, but an inseparable imbrication of, the private and the public. Warner (2002) also discusses the necessity of strangers to one's sense of self, when that self takes shape in relation to an idea of the public to which one belongs. This idea can also be articulated, using an attachment theory lesson, as the self's reliance on the mirroring back to itself by an imagined public. This public is simultaneously created by the idea, in the minds of its members, that it exists, and the work that it does in constructing its members.

Dean (2002), too, in her marvelous book on how publicity works in the internet age, writes about the ways subjectivity has been changed by the knowledge that countless others have access to (your) information, and the specific meanings made about this access by what she calls communicative capitalism. Zuboff's (2019) surveillance capitalism can be understood as the updated iteration of what was beginning in 2002, which, she (Zuboff, 2019) elucidates, was the nascent understanding that people's online activities could be translated into behavioral data that became the raw material for this new kind of capitalism. The monetization of surveillance begins with the new evaluation of online communication.

Dean (2002) argues that the secret is central to this world, where everything is connected and knowable, where the public can and should exercise their right to know. The idea that everything is knowable and shareable is given meaning only by the idea that something needs to be exposed. It is the secret which proves that "everything should be out in the open," by its very existence. If for Warner (2002), the fact of being addressed generates the public that is addressed thereby, for Dean (2002, pp. 10-11), "secrecy generates the very sense of a public that it presumes... it presupposes... that subject with a right to know." Either way, the idea of the public relies on something other than its own solidity to exist, and what it relies upon, one way or the other, is something individual, something hidden, something private. The private, the cordonedoff from the vast network of performance and visibility that constitutes the social world of the internet age, is implicated in the public eye. Under neoliberal imperatives, the private becomes an asset, and by now, under 
surveillance capitalism, the private's asset value is being actively tracked, mined, predicated and controlled for the purposes of generating profit (Zuboff, 2019).

Following Dean's (2002) formulation, this is a culture that is formed by the interaction between the idea of freedom as freedom of access to all information, and the idea of the secret that gives the notion of access its power. Implicit in this dynamic is both "a drive to be known, and the presumption that what matters is what is known" (Dean, 2002, pp. 12-13). People know they exist, she (Dean, 2002) argues, because they know their secrets are online. And as Zuboff (2019) has tracked, and as the many theorists cited above have argued, neoliberalism monetizes the individual who exists in this online context.

Dean (2002) says that the individual in technoculture is a cynical, ironic participant in these systems. She (2002) gives the example of participating in reward programs. We know the supermarket is doing it to make money, and that we are actually being "rewarded" very little while being interpolated into participating in making them that money. We do it anyway. Similarly, we do not have to actually believe that publicity indicates intrinsic value; we can know that it is the result of a media campaign or a reality TV show. But by participating in the structures that do this work, we participate in the valuing of publicity as a marker of worth, "materializing a belief through our actions even if we don't think we believe it" (Dean, 2002, p. 6). Drawing on the work of Zizek, Dean demonstrates how what we know is less important than what we do in the creation of ideological systems - such as the valuing of publicity as a marker of worth, even when we know that the whole thing is in the service of the generation of capital for the benefit of others. Zuboff (2019) adds an analysis of how surveillance capitalism wears us down as it profits from our behaviors, so that we become not ironic participants, but helpless puppets who do not believe we can change the power of technoculture over our lives. 


\section{Truth, Lies and Mediascape: Trump's Bullshit}

As I revise this chapter, America is reeling from a coup attempt on the Capitol on January 6, 2021.

This was a direct consequence of Donald Trump's penchant for "alternative facts," a ridiculous but dangerous bit of cognitive-dissonanceinducing phrasing coined by his erstwhile senior counselor Kellyanne Conway during an interview on January 22, 2017. A lie about the size of the crowd at Trump's inauguration was countered by Conway: "You're saying it's a falsehood... And [we] gave alternative facts" (Bradner, 2017, n.p.). Thereafter, alternative facts became available to spread false information.

Alternative facts are ideas about the world informed by emotion (what someone wished had happened, or wishes to profit from), not what actually occurred in a basic historical sense. It is no coincidence that the issue of the inauguration crowd size needed to be lied about, because it arose from Trump's narcissistic need for affirmation. From early in his presidency, Trump was resisting a world in which he was unpopular, tweeting in 2017, "Any negative polls are fake news" (Kurtzleben, 2017, n.p.). But the implications for Trump's insistence on bending the world to his will are far greater than the size of his ego.

Kurtzleben (2017) tracks how Trump's repurposing of the notion of fake news undermined, as intended, the ability of news media to speak to what he was actually doing. Instead, he created a world where what he wanted the public to believe is true became the driving force behind the point of a public sphere. Subjective emotion became the touchstone for what is real, at least for Trump's supporters, of which we now know there are over 70 million, given the amount of people who voted for him in the 2020 Presidential elections. And of course, the harnessing of emotion to manipulate people's beliefs and behaviors on a new scale was possible because of the internet (d'Ancona, 2017). Zuboff (2019) argues that surveillance capitalism has an investment in keeping users online, and that it recycles the information it garners about us in order to find and target users with the most emotionally inciting information. The use of 
emotion to generate an online audience is an imperative of the system, which Trump exploited.

The result, as Kurtzleben (2017) shows, is a dichotomous world of real fake news and fake fake news, with different definitions of the phrase being wielded online by the far right and by the left, resulting in one more way that different groups live in "increasingly different realities" (Kurtzleben, 2017). Dean (2002) rather accurately predicted how the excess of information and its relentless accessibility would result in the advent of the idea of fake news, which cynically manipulates a suspicion of information that can be produced anywhere, anytime, by anyone saying anything. That the truth no longer actually matters in this environment is evidenced by the finding that even when presented with the actual hard facts, voters do not necessarily change their conclusions, since what has been activated is connected to what voters already think about the issue being lied about (Barrera et al., 2020; in the case of this study, immigration in France). Voters' prior schemas guide their behavior, even after factual inaccuracies have been corrected; loyalty to Trump trumps actual facts (Swire et al., 2017). We are now in a "post-truth' era," driven by "ideological beliefs and 'common sense' assertions" (Harrison \& Luckett, 2019, p. 259); in other words, what we feel to be true (it is worth noticing that it is idiomatic in America to say, "I feel like..." instead of "I think that...").

Trump's use of rhetoric, a deliberately emotion-generation use of language (Mercieca, 2020; Rowland, 2019), capitalized on the dynamics inherent in modern technologies of communication, and the communities they create. He used emotion (Rowland, 2019) instead of, or to counter, fact-based reality. This is not to endorse the idea that absolute truth exists independent of the symbolic system through which we as humans make sense of the world. But it is to argue that the amount of people who attend an event, whether or not a massacre happened at a specific place and time, or the numbers of votes counted for one politician over another, can be treated as something nonnegotiable. These things belong to the realm of the real, and are not culturally mediated.

The rise of lies in the public sphere for the purposes of political gain has been specifically linked to Trump's 2016 presidential campaign and then his ascension to power (Ball, 2017). To be more specific, Davis 
(2017) differentiates between lies, which still bear some relation to the truth they distort, and bullshit, which contains no relation to external facts. Bullshit, he (Davis, 2017) says, has grown exponentially in the second decade of the twentieth century, culminating in the posttruth of Donald Trump's America.

The notion of alternative facts was not just rhetorical. It had real impact on the lives of marginalized people (Castrellón et al., 2017). It also functioned to disseminate both lies and bullshit via social media platforms and to normalize the onslaught of alternative reality, until the final lie that Trump had not lost the 2020 election to Joe Biden. Insisting repeatedly that he had won by a landslide and that the election had been stolen, Trump used emotion generated by bullshit to drive his supporters to violence in an attempt to overthrow the election results. This is typical demagoguery, but what is notable here is the use of the twenty-first century form of communication, and the kind of political public it enabled Trump to create. Trump's desire not to be a loser authorized a wholescale invention of reality, made solid through digital repetition. This is the world in which those born into the internet age must develop senses of selves.

\section{Being Millennial}

There is extensive discussion in the academic literature, the business and marketing journals, and online, about who exactly can or should be considered millennial. There are also well-placed warnings about taking the constructed notion of the "generation" as an absolute and absolutely accurate signifier. Nevertheless, generally speaking, millennials are taken to be those young adults born in the later 1970s and early 1980s, at the same time as neoliberalism began to take root. Sometimes, those born in the later 1980s and the 1990s are considered the next generation, or Gen Z (if millennials are Gen Y to Douglas Coupland's, 1991 Gen X). Now in their 20s and early 30s, millennials will soon be the largest group in the world's workforce. In addition, they, and their younger versions, are a focus of extensive corporate attention, so much so that it becomes difficult to separate out who the millennials "are" outside of the hype about 
them, a hype that is driven in most cases either by a gleeful focus on them as a market, or an idealized and optimistic construction of them as instantiating a new way of being thanks to the technology they live with.

Serazio (2015) warns against falling for the myth of the idea of a generation, especially now, in light of how constructed the millennial generation is by industries that want to market to them a sense of who they are or should be, and how to buy their way there, what he describes as a "project of power: summoning into being the consumer subject's sense of self so as to activate commercial activity from him or her" (Serazio, 2015, p. 601). We can see in this a version of Warner's (2002) public summoned into being by Zuboff's (2019) surveillance capitalism.

There is also the "kids these days" version of millennials and so-called Gen Zers, which bemoan their every behavior and collective value as degraded (see Bauerlein's, 2009, The Dumbest Generation: How the Digital Age Stupefies Young Americans and Jeopardizes Our Future [Or, Don't Trust Anyone Under 30]). The idea of the millennial generation, whatever its conceptual limits or false boundaries, has everything to do with the rise of the internet, and the accompanying new digital and social medias that have resulted in a new sense of what human being means.

The internet has brought with it new modes of subjectification, new ways of being that constitute a rupture with older ways of being individuals and of being social. Much of the writing about millennials asserts that growing up digital natives have wired millennials' brains differently. The idea of a generation shaped by access to the internet and all it entailsendless accessibility, global communities, apparent self-empowerment, the ability to influence the world on an unprecedented scale, the ability to connect across the surface of topics, images, links, and likes, automatic and effortless multitasking rather than depth thinking, cyberbullying, new forms of dopamine addiction, new forms of self-presentation and peer judgment, an expectation of interactivity in any learning experience, a psychological reliance on being instantly connected through smart phones, to name a few-is an idea whose power lies in the experiences of some members of this generation.

On May 20, 2013, Time Magazine ran a cover story entitled, "The Me Me Me Generation: Millennials are lazy, entitled narcissists who still live with their parents. Why they'll save us all” (Stein, 2013). 
Stein (2013) offers what starts out as a rollicking, sardonic put-down of this group. He says they are influenced by their peers to an unparalleled degree, to their detriment. Their use of technology has resulted in quantifiable lower creativity and empathy. And, he says, in an about-face that hinges on the ways he is also influenced by technology, they are more tolerant and nicer than previous generations, as well as close to their parents and unconcerned by authority in general. He sums up:

They're earnest and optimistic. They embrace the system. They are pragmatic idealists, tinkerers more than dreamers, life hackers. Their world is so flat that they have no leaders.... They want constant approval... They have massive fear of missing out... They're celebrity obsessed but don't respectfully idolize celebrities from a distance... They want new experiences... They are cool and reserved and not all that passionate. They are informed but inactive... They are probusiness... They love their phones but hate talking on them.

Many of these characteristics recur in descriptions and analyses of millennials, as we will see a little below. Many are also reductive or superficial descriptors of an inevitably more multifaceted group. Often left out is the difference material access makes - Stein (2013) says it makes no difference, but it always does. Warner (2002) makes the important point that the material form of the circulation of the texts that publics rely upon to exist, as well as the time that circulation takes, is a crucial component to bring to any understanding of a particular public. The consequences of the specific materiality upon which depends the ephemeral web, the digital cloud, are certainly relevant to any understanding of the nature of a public created by the digital media. Warner (2002) speculates briefly on this topic, in order to suggest that the internet may change the component of temporality in the constitutions of publics. A public is reliant on the channels of circulation it needs to perpetuate the discourse that creates it (Warner, 2002); access to computers and to internet literacy is a crucial, unspoken component of this process. The seamless navigation of this online public is a reality only for economically and socially enabled youth, on the global stage. 
Writers responding to Stein's (2013) article also pointed out the difficulty defining the parameters of who constitutes this generation, and especially the economic constraints many young people have to manage (see Hipp, 2016; Kendzior, 2016). These are good correctives to a conversation that is often either utopian or apocalyptic. I am leaving out of the picture those components of being millennial or younger that include crushing student debt, lack of access to affordable healthcare or stable work and ongoing financial dependence on parents not through choice, but through resultant necessity. It remains to be seen what difference the coronavirus pandemic will make to these systems. These are, however, important elements of this "generation's" experience to at least acknowledge in a discussion about their emotional reliance on a public sphere that is driven by a performance of self which depends upon the commodification of the personal or private.

What millennials are consistently defined by regardless of the tone or sophistication of the argument is their access to and comfort with technology. When it is celebrated, millennial culture is usually celebrated as a discontinuity from the past, a complete break, a revolution in thinking, learning and being caused by millennials being the first generation with unique access to and comfort with computers. Perhaps one of the most well-known cheerleaders for the digital generation is Tapscott (2009):

With their reflexes tuned to speed and freedom, these empowered young people are beginning to transform every institution of modern life. From the workplace to the marketplace, from politics to education to the basic unit of any society, the family, they are replacing a culture of control with a culture of enablement.

Their brains have been rewired in ways that make them smarter than their parents, indeed, "the smartest generation ever," and their influence on altering institutions is democratizing and fostering tolerance and diversity, he says. Tapscott's (2009) one concern was their lack of care over privacy, an attitude which may have changed in the intervening years, given how the internet has evolved (Zuboff, 2019).

He (Tapscott, 2009, p. 30) also notes they have changed "the concept of the brand" because, he says, of their insistence in participating in the 
process; they are not consumers, they are prosumers. Here is the line where the personal becomes not the political, but the commodifiable. Because it is clear that active participation and the insertion of agency into new media processes become a new way to market and sell both products and behavior via identity.

For Tapscott (2009), there is something intrinsic to the technology itself that causes creativity, connection, and new, better, ways of being in the world. This assumption about the technology itself as either good or bad, as seen in what it produces, is usefully called into question by Buckingham (2008; see his Growing Up Modern website). He warns of the dangers of a binary view of digital technology. He reminds us that there are, and always have been, continuities between old ways of doing things and new; that youth should not be romanticized; and that there is a material reality, or "digital divide" and not everyone who is young has equal access. He also points out that since the invention of electricity, at least, there has been a simplified debate about the benefits and risks of modern technology. This is an important set of caveats. What makes the difference, I think, what makes the current use of this technology potentially particularly pernicious, is the way the use of digital media has been so thoroughly saturated with market dynamics as imbricated with identity creation. As we have seen, Zuboff (2019) suggests that a new form of capitalism has resulted, which uses human behavior as its raw material. For generations who came of age in this universe, the implications for how they understand themselves and their relationships with others have been profoundly affected. This is not to argue that these technologies are only bad, or that they are intrinsically so.

But we are in a world where the potential of technology, whatever that means, has been thoroughly interwoven with the logic of profit, in the context of the crafting of a generation's (and future generations') psychological and social meanings, in their imaginings of themselves (Rizvi, 2006). The crafted definition of millennials as "digital natives" (the term was coined by Prensky, 2001, 2006, one of the cheerleaders of the revolutionary learning potential of computers) is dependent on not only their comfort with technology, but with the monetizing potential of this comfort. Here is an extract from a 2010 marketing report, entitled, "Millennials: Marketing to a Different Mindset": 
Millennials are inherently aligned with technology. Intimacy with the digital world is one of the greatest strengths of their generation. Never having known a world without digital technology, Millennials... experience the world in a completely different way than previous generations. They recognize the power and importance of social networks and utilize the Internet as a trusted source and a platform for self-expression. In the eyes of the Millennials, personal online networks hold as much importance and authority as any conventional media channel. (Qtd. Serazio, 2015, p. 605)

Personal online networks, therefore, are marshaled for revenue in ways previously confined to what used to be conventional media channels. Again, Zuboff's (2019) recent work gives additional context to this process, asserting that the online world developed within the logic of a new kind of capitalism which relies on both capturing and controlling our online behavior to provide the information about us that creates the markets we become. This commodity-generation logic in turn creates form and meaning for personal online networks: the chicken and the egg. Corporate marketing strategies create the image of what a successful millennial is as much as they refract it, what Serazio (2015, p. 604) calls, "the industrial construction of audiences." Millennials as an idea are a public, created as much by the idea of who they each are as members and as a group as they set the terms for their group. And crucially, whereas in earlier "generations," driving forces in the construction of the public might have been the polis, or nationalism, or even counterculture, always influenced by multiple social and economic forces, today it is unapologetically and primarily capitalist—or, as Zuboff (2019) would say, surveillance capitalist, where what is for sale is human behavior, generated through the control of our thoughts, feelings and habits.

In his work, Serazio (2015, p. 601) details "how millennials are 'generationed' by commercial interests through a prism of technological bias." Serazio (2015) also confirms what my own internet search suggested: that most of the thinking and writing - the knowledge-production-about the relationship between millennials and new media (online and digital technologies) is currently being produced by marketing companies and agencies, not by academics or scholars. Even the metadiscourse is directly commodified, so that most attempts to characterize and define 
millennials are by their buying potential or behavior, in order to suggest ways of branding products to speak to their identities in order to capture them as consumers. And not just as consumers, but as sources of profit whose senses of themselves are tied to the product being peddled, such that the relationship is not apparently a commercial one, but deeply personal: Tapscott's (2009) prosumers. Marketers and consultants are baldly discussing how to produce the sense of agency and participation for which millennials are famous in order to profit from it (Moreno et al., 2017).

Here is the abstract from a 2017 article in the International Journal of Marketing Studies:

The millennials constitute an important group of consumers. Therefore, to know how they behave has become an important issue. This paper aims to explain who the millennials are, to explain who belongs to this generational group and why they have become an attractive group for different social and economic sectors, by showing the most outstanding attitudes, tastes and buying behaviors... The findings suggest that millennials are a highly attractive market as they have grown up in an environment where technology provides a platform for personalization and immediate gratification in all aspects of life... The results contribute to the literature by providing a description of millennial consumers; showing in detailed the importance of this market segment and their buying behaviors. (Moreno et al., 2017, p. 135)

Serazio (2015) theorizes that new methods of selling to millennials increasingly commodify the cultural and the social, resulting in ways of being that make living and buying inseparable. He (Serazio, 2015, p. 600):

[I[lluminates how millennials are "sold" in a double sense: both the online promotional tactics used to target a cohort so often decried as unreachable through traditional channels as well as the stereotypes spun about this generation's values and behaviors that, cyclically, legitimate the commercial work that is produced for them. 
In his work on the constitution of modern publics, Warner (2002) also notices how more recent discourses explicitly commodify aspects of current youth and/or minority identities and cultural practices, so that the mass circulation of cultural ideas functions specifically as marketing. Marketing, display and subjectivity-creation become co-constituting. "You perform... your social placement... through [the deployment of commodified cultural memes]," says Warner (2002, p. 73).

The deployment of commodified cultural memes is otherwise known as the successful circulation of something "on brand." "Brand authenticity"; "brand community"; "brand meanings"; "brand image;" "brand trust;" "brand affinity"; "brand intimacy" and "brand advocate"; these are all terms that recur when people in business talk about attracting the millennial market. "A brand moment" means something important or meaningful has been captured, and, implicitly, rendered valuable because of its concomitant ability to get somebody to buy something, either now or upstream of the brand moment event. All of this brand energy coheres in the idea of the "personal brand"-how you present your experiences, biography, friend connections, likes and dislikes, avatars, photographs and life. Here is one of the consequences of the commodification of what was previously, in modernity at least, coded as the private, the intimate: who you are is for sale, and so the desirability of who you are is underwritten by its commodity value. It is likely quaint of me to be disturbed by this (although Zuboff, 2019 works hard to reinvigorate a sense of alarm about the turn capitalism has taken through the internet). It seems important to say, though, especially in the face of the broad characterization of internet culture as democratizing-although perhaps postTrumpism, this will change.

Dean (2002) suggests that as the promise of decentralized information access took on the flavor of a democratic revolution thanks to the advent of personal computing, a new kind of subjectivity was generated. One of the results, as I have been arguing, was a blurring of the line between public and private as realms of experience; the new technology brought with it new "idealized norms of publicity: communication, participation, and personalization," part of a new way of being: technoculture. But it also brought with it a new "mode of subjectification." The subject in the new digital age requires publicity to know that it exists as a subject: 
"People's experience of themselves as subjects is configured in terms of accessibility, visibility, being known. Without publicity, the subject of technoculture doesn't know if it exists at all," and, "Publicity in technoculture functions through the interpellation of a subject that makes itself into an object of public knowledge" (Dean, 2002, p. 90, p. 114).

The result of the internet age is not an enriched democratic public sphere. Instead, the result of vastly increased access to information is a new iteration of capitalism, which reaches inside the subject in new ways. The kind of communication now taken for granted on the internet produces a specific kind of public, which relies on specific ideas about its constituent members. These ideas include the assumption that the personal is and should be available for branding, and that the success of the brand is what the self depends upon to know itself. Information about all things is implicitly available, and also implicitly valuable especially insofar as it can attract marketable attention. Put another way, all attention is implicitly good because implicitly value-bearing because implicitly a revenue stream, either now or down the line, at the very least in the form of networks, whose publicity value is priceless for the self. The ultimate profiteerers from this new system are not human beings, but corporations (Zuboff, 2019), but this is obscured by a technoculture that normalizes being-for-profit.

What happens when the "nascent self is based upon mere marketed meanings" (Serazio, 2015, p. 603)? What are the consequences when the selves that are emerging in this culture are intertwined with the idea of the brand, not just as self-expression, but as self-knowledge, selfinstantiation, selfhood itself? What happens when identity becomes "a product of the brand" (Serazio, 2015, p. 609)? What are the implications when branded identity becomes valuable in relation to how much publicity it can garner to itself?

Young people need self-expression, and they need community; these are appropriate developmental requirements. These have been commodified and exploited in a concerted drive that "erodes clear borders between commerce and sociocultural life."

We ought to question the consequences of identity being channeled through digital branding schemes at such a critical developmental stage... 
In some ways, this networked hypersociality and participatory exhibitionism are perhaps just the latest manifestations of more enduring phenomena of youth when it comes to needs related to community and identity. Yet the interactivity endemic to digital media use maps usefully (for brands) onto these same critical developmental needs. (Serazio, 2015, p. 600; p. 603 ; p. 607)

Understanding that psychological processes - the centrality of mirroring to the ability to be a self; the reliance on community for all of us, and particularly at the vulnerable developmental stage of emerging from one's family and community as Western youth do-have been publicized and commodified in ways specific to how technology has come to be utilized in technoculture, is one way to answer the question of how new processes of subjectification are taking place. And this also helps me to understand some of the patterns I see in my therapy practice.

One of the populations I serve in my work as a psychotherapist in the San Francisco Bay Area is that group of millennials who either have, or are striving to be one of the ones that have made it in the tech industry which dominates the economy and the entrepreneurial youth culture here, or did until the coronavirus started to alter life in the Bay Area (Bowles, 2021). These are young adults in their late 20s and early 30s who live in a world where personal and career success are intimately tied to self-presentation, networking, selling one's personality as much as one's ideas: to, in a word, branding.

\section{Love and Money}

The observations which follow have not been based on a comprehensive quantitative study like Tapscott's (2009), who solicited hundreds of stories via Facebook, accessed networks of thousands of millennials on the internet and interviewed over 6000 people. Or Deloitte's Millennial Survey (2019), which interviewed over 13,000 young people in 42 countries. Instead, these comments are based on in-depth therapeutic relationships developed with clients, and on conversations with colleagues who also work with this population. 
I have been struck by the highly intelligent, highly resourced, highly educated, often (but not always) privileged young adults of this part of America who presented to the private therapy clinic where I first began to work with them as a group, and who I continue to see in private practice, with one of two emotional problems. Either they have made it in the tech world, working for or forming successful start-ups, weathering the pressures of self-presentation, getting good jobs with great salaries, and finding after committing all of themselves to their work that once they have achieved the prize, they are no longer sure of its meaning. These young adults are successful and miserable, feeling lonely, alienated, unsure of themselves, like they live in a world where they can never be sure which relationships are real. They feel pressured to socialize with people they do not like, and to be available for out-of-office interactions with bosses they do not respect, because the personal is the vehicle upon which they believe their commercial success rides. They do not have a sense of professional boundaries, and their interpersonal interactions at work are fraught with the need to manage office politics, grabs for power, their own ambitions, through the need to be likeable. Many of them seem to navigate the internal gap of, on the one hand, knowing they are part of an economic and social elite, and on the other, feeling unworthy-a version of imposter phenomenon. They tell me how incredibly well they have done, that they are living the start-up dream, and that they do not know who they are, exactly, or why this all should matter so much. They talk of feeling like there is a void inside them, or of feeling unaccountably depressed, or so anxious about work that they engage in maladaptive coping strategies that are making them miserable.

The other version of this I see are equally talented young people who have not yet made it, and fear they never will. Their fear of failure is woven into a fear of not being good enough, which does not mean not being smart enough, but not being likeable enough, not being lucky enough, not being connected enough. They know they are smart and talented, but they lack the networking knack, and/or they are haunted by having made the wrong choices and thereby not getting into the right elites to aid their careers. They often seem to be collapsing under the imperative to sell themselves, to measure the worth of one's life by the amount of profile and money one achieves, the sooner the more 
impressive and therefore the better. Those without the ego, the structural privilege, the charisma, the connections, the luck, or any necessary combination, feel like failures before they even begin, or cannot begin under the weight of the failure they feel.

Some of these psychological dynamics can be accounted for in terms of intrapersonal and family histories, to be sure. Some young people have parents for whom nothing was good enough; some have parents whose own failures haunt their children with the fear of who they might become if they do not succeed. Some come from poverty, or minority communities, and struggle with a sense of not belonging to the elite institutions and or corporate cultures they worked so hard to join. Some are immigrants, to whom American corporate individualism feels like an extremely uncomfortable costume they must wear. Some are female, which tends to bring with it a consistent struggle to embrace success while remaining feminine enough to be acceptable, and the necessity of navigating pervasive, unspoken misogyny and sometimes harassment. Taking up the right kind of space in the right kind of way is a particularly fine-tuned balancing act for some of these young women. The struggle to feel good enough in external settings has always been at least somewhat about a person's internal landscape, as well as the contexts in which that person must function. But there does seem to be a pattern here, or at least a similarity across people of the same, broadly millennial, generation.

The term "imposter phenomenon" was first coined in 1978, to describe a sense-of-self deficit experienced by high-achieving women of a particular class and race demographic, the usual WEIRD sample (Clance \& Imes, 1978). Its argument seems to me a more modern version of a point made by psychoanalyst Joan Riviere, in a 1929 essay entitled, "Womanliness as a Masquerade." Riviere (1929) argued, via a case study of a woman who might have been Riviere herself, that women seeking achievements and approval in "male" environments - that is, professional life- have to compensate for the gender anxiety this causes by assuming veneers of femininity. Wanting to be seen as worthy (worth attention, worth money, worth being seen) in public has long been a cause of anxiety for those assigned female at birth and raised as such. The reasons are somewhat obvious: there are different implications for women demanding the right to be looked at and valued in the public eye, worth 
intellectual and commercial respect. The stigma and violence against sex workers, but not their clients, illustrates what can be at stake for women who do not conform to normative gender rules for acceptable femininity, which include highly occluded access to active sexuality/inviting public attention/ambition. That these characteristics are in fact culturally connected in Western thought Freud's discourse made clear, and any investigation into the material history of authorship in the West illustrates (Distiller, 2008; Wall, 1993; see Zambreno, 2012 for a millennial exploration of these ongoing gender issues). It is worth remembering that "imposter phenomenon" initially had a gendered meaning, and was speaking specifically about women not feeling they deserved what they had achieved at work. While these issues remain pertinent as gender issues, the emotional processes described by the fear of being a fake in the public eye clearly by now have resonance across gender.

If the number of TED Talks on the subject of what is now usually called "imposter syndrome" is anything to go by, the concept has enormous valence in this culture. Its origins in gender difference have been ameliorated. Now, it seems, the majority of high achievers in the Western world (70\%, according to Solomon, 2016) suffer from not believing their achievements are based on solid ground. Many successful younger people in America struggle to believe they are worth what the public world of work says they are worth, even after hard work and sacrifice got them there. It seems they feel to some degree or another like they have faked their way to success, or like they are not as good as they appear to be.

Subsequent to the original 1978 study, which examined 150 mostly white middle and upper class professional and academic women, a literature has developed which applies the concept to other "minority" groups, and to men (McGregor et al., 2008). Recently, an exploratory 2018 study entitled, "Are all impostors created equal?" sets out to "Explor[e] gender differences in the impostor phenomenon-performance link." It found that imposter syndrome not only affects men too, but, in the study's terms, affects them worse. There are some comments that could be made about the interpretations in this exploratory study (men showed higher anxiety and less effort in response to their anxiety; women worked harder in response to the anxiety they felt, interpreted as indicating higher levels of suffering in the men). Most interesting to me here is that the cohorts 
recruited for the research are likely to be millennial, and were all from the United States: they were undergraduates from an American public university (Jarrett, 2018). Worth noting is that this study was framed in terms of its implications for how managers handle their personnel, once again linking the personal with the commercial.

Why are so many successful younger people convinced they have somehow fooled the world into thinking they are all that? Why do they feel that they are, in fact, charlatans and fakes? The original suggestionthat women struggle to navigate their socialized gender in the context of the public realm — needs another angle these days.

The feeling of having an internal void is a metaphor that seems to come up fairly often with my millennial clients. Why? Self-identification requires a relationship with another, ideally another that one recognizes is also another self rather than being experienced as an object, which causes problems in the process of finding oneself through the other (Benjamin, 1988; Bryson \& MacIntosh, 2010), as I have argued in previous chapters. What happens to this process of self-identification when the other is an internet public, and the self knows itself through its own commodification, that is, in order to be experienced as a self, it must experience its own objectification via " $[\mathrm{t}]$ he act of always performing oneself with an audience's potential response in mind and the need for reciprocal exchange" (Bryson \& MacIntosh, 2010, p. 115)?

The pathway to self-identification is not, in this symbolic universe, through a relationship with another self. It is through a relationship with a very specific kind of public idea of worth, of public reflection of worth. If the psychodynamic idea is that the subject reaches for the recognition of the other as a way to understand itself, perhaps the subject of technoculture suffers for reaching for the recognition of celebrity as reflected by an idea of many anonymous, networked, others, Warner's (2002) strangers. Relationship quality is not what matters here. Relationship quantity is. Alienation is the result. A sense of hollowness, an anxiety manifest in a restless, relentless superficial movement on the surface of things, across clicks and likes and happy photographs and carefully curated profiles.

Perhaps the internal feeling of the psychic void is the inevitable consequence when the self looks to find itself, not through repeated moments of neurobiologically felt presence, but through fame-based reflections in 
the imagined eyes of a digital public. There is no actual, embodied, there there. Instead there is a decentralized network whose psychic energy is the energy of constant, surface-based, movement. This kind of attention, by definition, is always on to the next thing. No wonder so many of my younger clients are anxious (APA, 2018).

Dean (2002) theorizes the underlying dynamics of celebrity in the technocultural symbolic economy by refiguring Lacan's ideas about desire and drive through the work of Zizek. In doing so, she accounts for the empty repetition for its own sake that characterizes much online activity: the technocultural subject is formulated by the endless, restless circularity of drive energy, not the lack at the center of the desiring subject which Lacan said propels us all into language and independent selfhood. Desire yearns for what it cannot have (in the first place, a feeling of wholeness, of return to the womb or union with the mother, according to Lacanian psychoanalysis. This loss lies at the heart of each of us, and propels us into human systems of meaning). Drive, a different kind of energy, creates restless movement in the attempt to fulfill its needs. The repetitive circle of the drive produces its own kind of empty pleasure. The circular energy of the drive becomes, in the imperative to celebrity, a "drive to make oneself seen that is crucial to publicity in technoculture." Desire impels the subject to look for the gaze of the other, but what desire cannot ever see is the point from which the other gazes; the subject cannot see the other's point of view. The energy of drive, in Dean's (2002) formulation, is the subject's work to make itself seen: "I make myself open, accessible, available, visible to that mysterious, unknown, secret thing, to the place from which I am gazed back at. In my very looking, I make myself visible to this object, the gaze" (Dean, 2002, p. 121). In my looking, I make myself visible to the gaze I need to know I exist (and which, by desire's definition, I cannot ever have). This seems to me a concise and resonant summation of the dynamics of self-constitution that millennials, those younger people who are trying to build human being in a universe structured by internet culture, have to navigate. This explains the internal void so many of them talk about.

Goodman (2020, pp. 341-2), in a discussion about how social media has altered subjectivity, recounts an experience with a student of his: 
The ocean was surging against the rocks... I was enamoured with the intensity and grandness of what I was beholding. I turned to see my student pointing her phone at the water and heard her whisper "come on water, do something exciting."... She expressed that these experiences feel most real when she is able to capture them and show her friends through her social networks. She feels uneasy when she does not have this mechanism of expression... Later at dinner, she "checked in" on Facebook to allow her friends to know where she was. There was a way in which she did not feel as though she was sitting at the restaurant unless others knew her location.

Dean (2002) brings this reflexivity-I make myself seen in order to see myself being seen - into her definition of technocultural celebrity, which she says is an integral part of how publicity works in this culture. Celebrity is about being known for being known. "In celebrity, publicity is reflexivized, turned back on itself such that not only is something seen, but it makes itself seen-accessible to, information for-others." Because technocultural publicity is driven by the energy of celebrity, the subject produced by technoculture is itself "configured by celebrity" (Dean, 2002, p. 122, p. 13). The mediated performance of the private lives of celebrities fuels this desire and imperative to be seen publicly in order to exist. It flavors the public's idea of itself, its members and its members' ideas of themselves as members of this public.

In December 2018, Rolling Stone carried a cover story about Shawn Mendez, which it billed as "confessions of a neurotic pop idol." Mendez is the very young (16 when he achieved pop stardom) Canadian who became famous "not long after he picked up a guitar for the first time" by "drawing half a billion views" on Vine, a social media app which allowed him to post 6-second versions of other people's pop songs (Doyle, 2018).

The article presents us with an anxious young man who does not quite believe his own success, which Doyle gestures toward by quoting specific lyrics from the Bruno Mars song that Mendez sang the first time he sang in public: "Easy come, easy go!” (Doyle, 2018). These lyrics suggest the ephemerality of Mendez's position by underscoring its genesis in internet celebrity. The house of cards nature of whole enterprise is implicit in its 
very nature, and this, Doyle slyly suggests, accounts for Mendez's ongoing, underlying anxiety, or his "neurosis."

The story starts by recounting to us a daily encounter between Mendez and the world of social media which made him famous:

Shawn Mendez was up late in his hotel room a few nights ago, scrolling through photos online. He kept seeing Top 40 A-listers with their partners... and he was starting to get a little jealous. "I had this thought: 'I have to get paparazzied with someone. Who am I gonna get? I'm not relevant". (Doyle, 2018)

Doyle addresses the subtext that Mendez was made by the internet public and needs to keep courting its attention:

It's easy to be skeptical of his success- just ask Mendez, a self-described "extremely neurotic" 20-year-old who spends much of his time secondguessing his career choices. "It's literally my biggest fear, to wake up tomorrow and nobody cares," he says. (Doyle, 2018)

Mendez's celebrity, and its vulnerabilities, exemplifies the way things now are for people seeking success online. He is one of the more successful ordinary people whose internet access brought him fame and riches. One of the rules he has to keep himself "on track... as he tries to build the long-term career of a Sheeran or a Taylor Swift" is, "Never say no to a selfie."

When he walks out of the lobby of the... [h] otel..., there are already a few dozen girls waiting by the entrance. "Hold on," Mendez tells his team. "I gotta take some photos." After a minute or two of efficient chitchat"You're amazing!" he tells one fan...- he makes his way to the van. (Doyle, 2018)

Mendez's availability to his fans is as much a part of his career profile as his music. Accessibility of his person is part of his success strategy. This is packaged as a personal exchange, where he pretends to recognize and value an individual fan's subjectivity. He is like the early modern poet, invoking his patron in language of intimacy in order to further his career, 
which specifically means enable the conditions of production to create something artistic (writing in the one instance, music in the other). He is also the quintessential millennial subject, caught in the endless cycle of offering himself up, through pseudo-connection, in order to ensure his commercial existence. His bankability is his likeability. How well can he make her feel connected to him? How efficiently? Because the more the better. In fact, the more connections he makes, the more he needs to keep up with the connections, because if they go away, so does "Shawn Mendez, pop idol" (Doyle, 2018).

Mendez's commitment to his fans, his willingness to always pose for selfies, suggests he is driven by technocultural celebrity. He has to have his celebrity seen by the public in order for it to exist, and he has to work constantly to tend to it in these precise terms. And Rolling Stone's (2018) offer to present us with his "Confessions" contributes to the work of technocultural subject-production through the idea of accessible information, as Dean (2002) suggested. We are offered access to his secrets, which make his manufactured selfhood (seem) real and authentic. If we can access the real Shawn Mendez, the person himself, we can feel we know him, feel closer to him, know something about him and so reinscribe his celebrity by participating in the commercial exchange of personhood. We can feel connected to the pop idol who exists because we feel connected to him. Our connection to his celebrity feeds into our own awareness of our existence.

This explains his anxiety, an existential awareness of the reliance of his very existence as "Shawn Mendez... pop idol" (Doyle, 2018) on an endless reflexivity, where his work's value is not in the work, but in the extent to which the work ensures that his fans are interested in looking at him. And by "work" I mean to invoke not only his music, which he also writes, but the constant, ceaseless work of self-assertion, self-presentation, selffashioning (Greenblatt, 1984) that was always the core of his celebrity.

Doyle describes the original publicity work Mendez did, at Meet and Greet Conventions where, along with people who were famous for vandalizing supermarkets, he participated in "a platform for teen boys with large social followings to meet the fans who felt as though they already knew them... 'We were like zoo animals,' he says. [Fans] would just stare at us and take photos with us. We would do whatever they say" (Doyle, 
2018). Somehow, this is supposed to be different from, if precursor to, what happens now:

A wave of shrieks erupt from the parking lot. Hundreds of girls have their phones ready... Mendez takes a picture with each one, a smile pasted on his face. After he works his way through, he blows one last kiss and gets in the next van... "It's pretty dope here," he says, then goes quiet for a while. "I don't know, man," he mumbles as we approach the hotel. "I feel fucking weird". (Doyle, 2018)

I am struck, in these descriptions, by how both parties are willingly participating in an exchange which they know is not about their actual selves being seen, but about a commodified, branded interaction: Mendez pretends to care about each fan, and in return they award him celebrity. He serves up his personality, or a version of it, and in return they feel seen by him, connected to him. Some of this is, of course, typical to any dynamic of fandom. What is specific here is how it needs to be endlessly recorded and disseminated for each party to reap their full investment in the exchange. That Mendez seems to know this, and that Doyle certainly does, is encoded in the final quote above_- "I don't know, man," he mumbles... "I feel fucking weird" — which ends a section of the story.

Mendez is presented as suffering from anxiety and a kind of inexplicable depression: "You know when you're in a state of unhappiness when you have no reason to be unhappy?' he says. 'I hate that'” (Doyle, 2018). He comes across as sweet, kind, and utterly devoted to his own success, which is going well. And yet, unhappy. Mendez, of course, is barely millennial-but he is the next incarnation. His antidote to the depression, Doyle (2018) reports, is to pretend he is on stage, with "'people that love me."”

The story ends with a tale of Mendez hooking up with a bartender for a night, and how "fans have even begun speculating about the bartender, because he followed her on Instagram that night."

Actually, he adds, he didn't: when Mendez was in the bathroom, she grabbed his phone and followed herself from his account. He shakes his head. "Gotta give her credit for that". (Doyle, 2018) 
And those are the closing words of the story. The bartender's exploitation of their intimacy, however fleeting, deserves grudging credit. Because Shawn Mendez should and does expect to have his celebrity self profited from, hall of mirrors style. This is the world he lives in.

The structural imperative to publicity demanded by the internet in the lives of all the characters is woven through this account, unremarked, but clearly telling the story of Shawn Mendez, the "neurotic pop idol." It is a story, as I have been suggesting, that illustrates Dean's (2002) theoretical model of how technoculture works to produce subjects, dependent on a kind of publicity that is constituted by twenty-first century celebrity. To this formulation I have added two characteristics of the subjects of this culture: that their love and friendship, their intimacy and connections, their personalities, are fundamentally commodities; and that they are inexplicably anxious, even when they seem to have everything they have worked for. The reasons connect through the effects of technoculture on the kind of subjectivity that can be found in this symbolic economy. It knows its own fakeness, and so does everyone else. It does not have to believe in itself. The system believes for it. But at the end of the day, it feels its own precarity. It senses the void underneath all that anxious, selfreflexive, self-fueling drive energy.

There is another component of Mendez's story that is instructive. Shawn Mendez has garnered an awful lot of online attention which speculates on his sexuality, or as he tells Doyle (2018), “This massive, massive thing for the last five years about me being gay." Doyle explains: "Examples of what he means are all over YouTube and Twitter. There are memes that pair photos of Mendez with jokes about being closeted and videos that scrutinize his gestures" (Doyle, 2018).

Mendez describes being extremely affected by this coverage. He:

$[\mathrm{O}] \mathrm{ften}$ finds himself watching his own interviews, analyzing his voice and his body language. He'll see an anonymous stranger comment on the way he crosses his legs once and try not to do it again. (Doyle, 2018)

Doyle recounts how his attempt to address the issue directly, that is, via Snapchat, backfired, and Mendez's panic after allowing Taylor Swift to post a video of her putting makeup on him: 
He told her it was fine without thinking, but later that night, he woke up in a cold sweat. "I felt sick," he said. "I was like, 'Fuck, why did I let her post that?' I just fed the fire that I'm terrified of”. (Doyle, 2018)

Once again, incidentally, we are reminded of how carefully celebrities have to consider and curate the information they release about themselves. But most interesting here is Mendez's horror of being considered gay when he is not. If he is not, as he insists, gay, then what is a stake, especially in his demographic, where sexual and gender fluidity is more available to public figures than ever before (see the treatment of Harry Styles in Vanity Fair a couple of years later, Vanderhoof, 2020)? I am not dismissing the ongoing reality of homophobia and gender-related phobias, and Mendez himself acknowledges that he is uncomfortable with the homophobia he knows his response demonstrates (Doyle, 2018). But cold sweats and sickness because of a misrepresentation of this most personal of qualities? This is the distress of misattunement, of looking into the eyes of the mirroring other and seeing something that you know is wrong reflected back at you. It is a feeling of wrongness that causes anxiety, depression, self-loathing — as queer, trans, and nonbinary folk know very well. It is further evidence that Mendez's selfhood is being formulated by this public presentation of his celebrity self, that the personal and the public, and the valuing of the inner self through commercial/celebrity success, are all dependent on each other in this world.

"Easy come, easy go": Perhaps it also lets us know that Shawn Mendez, despite how hard he has worked, also feels like he may be exposed as not all that, if he doesn't play his cards exactly right. If he cannot succeed in controlling representations of the celebrity self that create him by circulating through his fandom, will he continue to exist as a celebrity? Is imposter syndrome so much a part of this culture because its version of subjectivity depends, by definition, on the condition of celebrity? I am not presuming to diagnose Shawn Mendez, I am speculating, using this article about him as a cultural text: If the self is dependent on its public to underwrite its value, and its public is fed by the curation of the self as product, it makes sense that the person underneath all that would feel like the image had taken over. 
Dean (2002) links the centrality of the promise of celebrity to the work of subjectivization it does, to "the fundamental diversity and opacity of cyberspace: we are known, but the terms of this being known are never transparent to us" (Dean, 2002, p. 122). She details the sense we all have of knowing there is information about us online that we cannot control the circulation or the content of (Zuboff, 2019 adds horrifying and extensive detail to exactly how and why this happens). She names the "insecurity" this causes_- "How, exactly, are we being looked at? One never really knows who one is" (Dean, 2002, p. 123). If the internet says you are gay, does that make you so? If the internet says you are gay, does that affect your brand? In ways you cannot control? What other secrets might it make up about you? How will this affect how you are seen? It is worth noting here that we have indeed experienced technoculture as a place where reality is invented through online repetition, the key to Trump's political brand.

The subject's only option to ensure its existence is "to make itself visible over and over again. It has to understand itself as celebrity, precisely because the excess of cyberia makes it uncertain as to its place in the symbolic order" (Dean, 2002, p. 123). This is what makes Shawn Mendez like "us", and "us" like Shawn Mendez, because his celebrity was crafted by and through the internet. Mendez could easily be one of my clients: his anxiety about his own existence as "Shawn Mendez, pop idol," his ongoing commitment to keeping himself in the eye of a public that exists as an uncontrollable, fragmented gaze to which he must continually offer his self in order to make his music, and his money, these feel familiar. Technocultural celebrity doubts itself, because it is reliant not only on knowing one is known but on knowing one is not in control of how, where, when, and why one is known. Hence Shawn Mendez, terrified of being thought to be gay, anxiously monitoring his own existence insofar as it can be sustained online and through social media.

Celebrity is not a true source of identification, says Dean (2002). It is not analogous to being mirrored, because the source of the gaze in which one seeks oneself is "a point hidden in an opaque and heterogenous network. One is compelled to make oneself visible precisely because of the uncertainty as to whether one registers at all" (Dean, 2002, p. 124). Perhaps this is the central change wrought on millennial personhood by 
the computerized online world millennials have always traversed. What has been lost, more even than daily opportunities for human connection, is personhood based on personhood, people who are people because of other people. Instead, people are reliant on anxiously offering a commercialized version of themselves to a fragmented and unknowable network, whose attention is uncertain, capricious, and, unless constantly reengaged by ongoing content, brief. And to reiterate, Dean's (2002) celebrity is not a simple desire for fame; it is a fundamental reliance on being known in a system where the subject cannot know or control how she is known, by whom, or why. This subject knows the public who sees her is multiple, fragmented, often hostile, often misinterpreting the information she cannot control about herself that is being shared out there. It is a self who needs to see she is seen before she can know she exists, but not in the way in which the infant is reliant on mirroring to organize her internal landscape, to learn the meaning of her experience and how to manage it. The millennial self subjectivized through celebrity is eternally anxiously caught in the circular drive to attract the right kind of attention in order to achieve its goals. And being successfully interpolated by this system, succeeding in knowing oneself because one knows, for a moment, that one has been seen, is by definition to trivialize oneself, to reduce oneself to being just another transient piece of content in an endless series of replaceable stories. Success in this system cannot but become devalued as human experience by its inevitable commodification. Every piece of content will know it is successful when it becomes the next "scoop" (Dean, 2002, p. 129). Success is successful, transient posturing.

Goodman (2020, p. 333) asks precisely the question, has the new technology, with the ways it has undoubtedly shaped human interaction, enabled "a new epoch in the shape and nature of human subjectivity, intimacy, and desire?" He answers by suggesting that psychic distance, invisibility, and invulnerability have always been elements of Western subjectivity, which during the Enlightenment came to inform the value placed on rationality and self-containment, Descartes' self-enclosed thinking subject. Not incidentally, this self, able to control what he thinks and wants, but free from being seen or controlled, unconnected to or implicated in other selves, is a subject who creates and uses others. The selfcontainment enables objectification of other subjects. Goodman (2020, 
p. 336) thus locates the internet's mediated and avatar-based interactions not as something new, but as a radical continuation of elements in Western culture, where "we get to manage and modulate our presence."

The difference now, he suggests, is in how the subject feels compelled to make itself visible, to be seen in order to know that it exists through public declaration. Unlike attachment mirroring (In the world of social media, "Experience [becomes] owned by the recognition of a nonparticular other" Goodman, 2020, p. 342), the way this is playing out in the new public sphere dislocates, to use Goodman's (2020, p. 337) word, subjectivity from connection, and refashions it as, in my word, brand:

I can "post" myself in the manner most conducive to my desire and to what I perceive to be the desire of others. I make myself more consumable. I become more of a commodity. What is more desirable in a capitalistic, free market economy? (Goodman, 2020, p. 337)

In other words, Goodman continues to describe the implications of neoliberalism, working together with our new technologies and the new forms of capitalism that are resulting, for human subjectivity in the twentyfirst century. This will inevitably affect those born into this world more intensely than those of us initially formed in a previous iteration of this culture. As Goodman (2020, p. 344) concludes, "With the advent of personal computing devices, modern technology has become a central mediating force within human exchange, and with it, human subjectivity... The norms of connection, intimacy, and public/private experience are shifting."

To this I would reiterate that we need to bear in mind the material investments implicit in these shifts. These new developments grow out of and intensify neoliberal dynamics. Neoliberalism is itself an end-product of colonialism, which was enabled by the philosophies and economies of the Enlightenment. In Zuboff's (2019) account, we are being newly colonized by a new kind of capitalism which uses the technology of the twenty-first century to render human being itself as profit, and truncate our ability to have agency over our selves. Our behaviors are both mined and moderated. This brave new world runs the risk of collapsing our chances to think complicitously about ourselves, our world, each other.

That this is indeed happening among younger users in ever more intensive ways is evidenced by brown's (2020) recent response to the advent of 
cancel culture online. She (brown, 2020) issues an appeal to progressive online users to tolerate each other's mistakes, engage productively in conflict rather than shut each other down, and not to reproduce the punitive and annihilating systems that structure the state's relationship to its others, which she (brown, 2020) identifies as unconscious identification processes at work in these online communities. It is only by recognizing how we are all implicated in all of the systems at play here that we can resist its historically familiar terms. None of us is better than the other.

I write this as Joe Biden is about to be inaugurated. I write it with a sense of dread and the disempowerment Zuboff (2019) argues is a consequence of the workings of surveillance capitalism. This new force requires people to be engaged online and creates imperatives to do so. She (Zuboff, 2019) also tracks how the development of twentieth century industrial capitalism, which transmuted into neoliberalism, favored machines over people. This choice created an economically and thus socially disempowered class of Americans who previously had voice and earning potential, developed, I would add, in a society that had always conferred racialized privilege. Zuboff's (2019) economic history, together with the structuring history of white supremacy in America outlined in Chap. 3, seems to me intimately connected to the communities Trump and Trumpism have marshaled online and on the streets (Parmar, 2021). I fear that we are further than ever from a shared vision of human complicity, where hatebased othering processes are rejected as hurtful to everyone, and where human being can be experienced differently to the inheritances handed down to us by the racism and misogyny of colonialism, and the destructive, entitled individualism that found its most powerful instantiation in neoliberalism.

\section{Works Cited}

American Psychiatric Association. (2018). Americans say they are more anxious than a year ago; Baby Boomers report greatest increase in anxiety. Retrieved January 6, 2021, from https://www.psychiatry.org/newsroom/news-releases/ americans-say-they-are-more-anxious-than-a-year-ago-baby-boomersreport-greatest-increase-in-anxiety 
Anderson, B. (1991). Imagined communities: Reflections on the origins and spread of nationalism. Verso.

Ball, J. (2017). Post-Truth: How bullshit conquered the world. Biteback Publishing. Barrera, O., Sergei Guriev, S., Henry, E., \& Zhuravskay, E. (2020). Facts, alternative facts, and fact checking in times of post-truth politics. Journal of Public Economics, 182, 1-19.

Bauerlein, M. (2009). The dumbest generation: How the digital age stupefies young Americans and jeopardizes our future (or, don't trust anyone under 30). Penguin.

Benjamin, J. (1988). The bonds of love: Psychoanalysis, feminism and the problem of domination. Random House.

Bowles, N. (2021, January 14). They can't leave the Bay Area fast enough. New York Times. https://www.nytimes.com/2021/01/14/technology/sanfrancisco-covid-work-moving.html

Bradner, E. (2017, January 23). Conway: Trump White House offered "alternative facts" on crowd size. CNN Politics. Retrieved January 12, 2020, from https://www.cnn.com/2017/01/22/politics/kellyanne-conway-alternativefacts/index.html

brown, a.m. (2020). We will not cancel us: And other dreams of transformative justice. AK Press.

Bryson, M. K., \& MacIntosh, L. B. (2010). Can we play Fun Gay? Disjuncture and difference, and the precarious mobilities of millennial queer youth narratives. International Journal of Qualitative Studies in Education, 23(1), 101-124.

Buckingham, D. (2008). Introducing identity. In D. Buckingham (Ed.), Youth, identity and digital media (pp. 1-19). MIT Press.

Buckingham, D. (n.d.) Growing Up Modern. Retrieved January 13, 2021, from https://davidbuckingham.net/growing-up-modern/

Burke, P. (1997). Representations of the self from Petrarch to Descartes. In R. Porter (Ed.), Rewriting the self: Histories from the Renaissance to the present (pp. 17-28). Routledge.

Calancie, O., Ewing, L., Narducci, L. D., Horgan, S., \& Khalid-Khan, S. (2017). Exploring how social networking sites impact youth with anxiety: A qualitative study of Facebook stressors among adolescents with an anxiety disorder diagnosis. Cyberpsychology: Journal of Psychosocial Research on Cyberspace, 11(4), article 2.

Castrellón, L. E., Rivarola, A. R. R., \& López, G. R. (2017). We are not alternative facts: Feeling, existing, and resisting in the era of Trump. International Journal of Qualitative Studies in Education, 30(10), 936-945.

Clance, P. R., \& Imes, S. A. (1978). The imposter phenomenon in high achieving women: Dynamics and therapeutic intervention. Psychotherapy: Theory, Research \& Practice, 15(3), 241-247. 
Coupland, D. (1991). Generation X: Tales for an accelerated culture. St Martin's Press.

Cushman, P. (2019). Travels with the self: Interpreting psychology as cultural history. Routledge.

d'Ancona, M. (2017). Post-Truth: The new war on truth and how to fight back. Random House.

Davies, W. (2016). The happiness industry: How the government and big business sold us well-being. Verso.

Davis, E. (2017). Post-Truth: Why we have reached peak bullshit and what we can do about it. Little, Brown Book Group.

Davis, J. E. (2020). Let's avoid talk of "chemical imbalance": it's people in distress. Psyche. July 1, 2021, from https://psyche.co/ideas/lets-avoid-talk-ofchemical-imbalance-its-people-in-distress

Dean, J. (2002). Publicity's secret: How technoculture capitalizes on democracy. Cornell University Press.

Deloitte Millennial Survey. (2019). Retrieved January 13, 2021, from https:// www2.deloitte.com/nz/en/pages/about-deloitte/articles/millennialsurvey.html

Distiller, N. (2008). Desire and gender in the sonnet tradition. Palgrave Macmillan.

Docu, V. (2018). Millennials and anxiety: An exploration into social networking sites as a predisposing factor. Romanian Journal of Cognitive Behavioral Therapy and Hypnosis, 5(1-2), 1-11.

Doyle, P. (2018, November 26). Shawn Mendez: Confessions of a neurotic pop idol. Rolling Stone. Retrieved January 13, 2021, from https://www.rollingstone.com/music/music-features/shawn-mendes-cover-interview-756847/

Eisaman Maus, K. (1995). Inwardness and theatre in the English Renaissance. University of Chicago Press.

Erikson, E. H. (1968). Identity, youth, and crisis. WW Norton.

Febvre, L., \& Henri-Jean, M. (1979). The coming of the book: The impact of printing 1450-1800. NLB.

Ferry, A. (1983). The "inward" language: Sonnets of Wyatt, Sidney, Shakespeare, Donne. University of Chicago Press.

Fiedler, L. (1973). The stranger in Shakespeare. Stein \& Day.

Fineman, J. (1986). Shakespeare's perjured eye: The invention of poetic subjectivity in the sonnets. University of California Press.

Foucault, M. (1977). What is an author? In D. Bouchard (Ed.), Language, counter-memory, practice (pp. 113-138). Basil Blackwell. 
Gill, R., \& Orgad, S. S. (2018). The amazing bounce-backable woman: Resilience and the psychological turn in neoliberalism. Sociological Research Online, 23(2). https://doi.org/10.1177/1360780418769673

Goodman, D. M. (2020). The pornographic self: Technology, vulnerability, and "risk-free" desire. In D. Goodman \& M. Freeman (Eds.), Psychology and the other (pp. 332-347). Oxford University Press.

Greenblatt, S. (1984). Renaissance self-fashioning. University of Chicago Press. Harrison, N., \& Luckett, K. (2019). Experts, knowledge and criticality in the age of "alternative facts": Re-examining the contribution of higher education. Teaching in Higher Education, 24(3), 259-271.

Harvey, D. (2007). A brief history of Neoliberalism. Oxford: Oxford University Press.

Hipp, P. (2016). Fuck you, I'm not a millennial. Retrieved January 13, 2021, from https://medium.com/@thehipp/fuck-you-i-m-not-a-millennial-e92 e653ceb39

Horning, R. (2015, August 12). Do the robot. The New Inquiry. Retrieved January 7, 2021, from http://thenewinquiry.com/blog/do-the-robot

Huntington, J. (2001). Ambition, rank, and poetry in 1590s England. University of Illinois Press.

Jarrett, C. (2018). Research Digest. June 1. A new study claims that, under pressure, imposter syndrome hits men harder than women. Retrieved January 12, 2021, from https://digest.bps.org.uk/2018/06/01/a-new-study-claimsthat-under-pressure-imposter-syndrome-hits-men-harder-than-women/

Kendi, I. X. (2016). Stamped from the beginning: The definitive history of racist ideas in America. Bold Type Books.

Kendzior, S. (2016, June 30). The myth of millennial entitlement was created to hide their parents mistakes. Quartz. Retrieved December 28, 2020, from https://qz.com/720456/the-myth-of-millennial-entitlement-wascreated-to-hide-their-parents-mistakes/

Kurtzleben, D. (2017, February 17). With "fake news" Trump moves from alternative facts to alternative language. NPR Politics. Retrieved January 12, 2021, from https://www.npr.org/2017/02/17/515630467/with-fake-news-trumpmoves-from-alternative-facts-to-alternative-language

Marotti, A. (1986). John Donne: Coterie poet. University of Wisconsin Press.

Marotti, A. (1995). Manuscript, print, and the English Renaissance Lyric. Cornell University Press.

McGregor, L. N., Gee, D. N., \& Posey, K. E. (2008). I feel like a fraud and it depresses me: The relation between the imposter phenomenon and depression. Social Behavior and Personality, 36(1), 43-48. 
Melluish, S. (2014). Globalization, culture and psychology. International review of psychiatry, 26(5), 538-543.

Mercieca, J. (2020, June 19). A field guide to Trump's dangerous rhetoric. The Conversation. Retrieved January 18, 2021, from https://theconversation. com/a-field-guide-to-trumps-dangerous-rhetoric-139531

Mokyr, J., Vickers, C., \& Ziebarth, N. L. (2015). The history of technological anxiety and the future of economic growth: Is this time different? Journal of Economic Perspectives, 29(3), 31-50.

Moreno, F. M., Lafuente, J. G., Carreón, F. A., \& Moreno, S. M. (2017). The characterization of the millennials and their buying behavior. International Journal of Marketing Studies, 9(5), 135-144.

Parmar, I. (2021, January 11). The Trump coup d'etat and insurrection was long in the making, and will continue. The Wire. Retrieved January 18, 2021, from https://thewire.in/world/the-trump-coup-detat-and-insurrectionwas-long-in-the-making-and-will-continue

Perry, I. (2018). Vexy thing: On gender and liberation. Duke University Press. Prensky, M. (2001). Digital natives, digital immigrants. On The Horizon, 9(5), 1-6.

Prensky, M. (2006). Don't bother me, mom - I'm learning! Paragon House.

Riviere, J. (1929). Womanliness as a masquerade. The International Journal of Psychoanalysis, 10, 303-313.

Rizvi, F. (2006). Imagination and the globalisation of educational policy research. Globalisation, Societies and Education, 4(2), 193-205.

Rose, N. (1998). Inventing our selves: Psychology, power, and personhood. Cambridge: Cambridge University Press.

Rowland, R. (2019). The populist and nationalist roots of Trump's rhetoric. Rhetoric \& Public Affairs, 22(3), 343-388.

Rutherford, A. (2018). Feminism, psychology, and the gendering of neoliberal subjectivity: From critique to disruption. Theory \& Psychology, 28(5), 619-644. Saunders, J. W. (1951). The stigma of print: A note on the social bases of Tudor poetry. Essays in criticism, 1, 139-164.

Schalkwyk, D. (2008). Shakespeare, love and service. Cambridge University Press. Schore, A. (2012). The science of the art of psychotherapy. Norton.

Serazio, M. (2015). Selling (digital) millennials: The social construction and technological bias of a consumer generation. Television \& New Media, 16(7), 599-615.

Solomon, L. (2016). The surprising solution to the imposter syndrome. TEDXCharlotte. Published November 30.

Stein, J. (2013, May 20). The Me Me Me Generation: Millennials are lazy, entitled narcissists who still live with their parents. Why they'll save us all. Time. 
Retrieved January 11, 2021, from http://content.time.com/time/subscriber/ article/0,33009,2143001,00.html

Sugarman,J.(2020). Neoliberalismand theethicsof psychology.InD.M.Goodman, E. R. Severson, \& H. Macdonald (Eds.), Race, rage, and resistance: Philosophy, psychology, and the perils of individualism (pp. 73-89). Routledge.

Sweet, E. (2018). "Like you failed at life": Debt, health and neoliberal subjectivity. Social Science \& Medicine, 212, 86-93.

Swire, B., Berinsky, A. J., Lewandowsky, S., \& Ecker, U. K. H. (2017). Processing political misinformation: Comprehending the trump phenomenon. Royal Society Open Science, 4(3), 1-21.

Tapscott, D. (2009). Grown up digital: How the net generation is changing your world. McGraw Hill.

Vanderhoof, E. (2020, November 12). Harry Styles confirms that he is 2020's ideal mascot. Vanity Fair. Retrieved January 19, 2021, from

Wall, W. (1993). The imprint of gender: Authorship and publication in the English Renaissance. Cornell University Press.

Warley, C. (2005). Sonnet sequences and social distinction in Renaissance England. Cambridge University Press.

Warner, M. (2002). Publics and counter publics. Public Culture, 14(1), 49-90. Zambreno, K. (2012). Heroines. Semiotext(e).

Zuboff, S. (2019). The age of surveillance capitalism: The fight for a buman future at the new frontier of power. Profile.

Open Access This chapter is licensed under the terms of the Creative Commons Attribution 4.0 International License (http://creativecommons.org/licenses/ by/4.0/), which permits use, sharing, adaptation, distribution and reproduction in any medium or format, as long as you give appropriate credit to the original author(s) and the source, provide a link to the Creative Commons licence and indicate if changes were made.

The images or other third party material in this chapter are included in the chapter's Creative Commons licence, unless indicated otherwise in a credit line to the material. If material is not included in the chapter's Creative Commons licence and your intended use is not permitted by statutory regulation or exceeds the permitted use, you will need to obtain permission directly from the copyright holder.

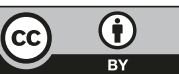

